\title{
Ressignificação de móveis e objetos de decoração - relato de uma experiência de trabalho de conclusão de curso em Design de Interiores
}

\author{
Resignification of furniture and decoration objects - an Interior Design project report
}

RODRIGUES, Aline Alves; Graduação; Instituto Federal de Minas Gerais - campus Santa Luzia

enilarodrigue@yahoo.com.br

BARBOSA, Paula Glória; Mestre; Instituto Federal de Minas Gerais - campus Santa Luzia

paula.barbosa@ifmg.edu.br

BRITO, Thábata Regina de Souza; Mestre; Centro Universitário UNA

thabata.brito@prof.una.br

\section{Resumo}

Este trabalho apresenta uma discussão sobre o processo de reutilização de móveis e objetos de decoração por meio da ressignificação, objetivando incitar práticas no campo do Design de Interiores que estejam alinhadas com as demandas contemporâneas de sustentabilidade. $\mathrm{Na}$ contramão da obsolescência programada, da produção excessiva de lixo e do uso indiscriminado dos recursos naturais, propõe-se que produtos candidatos ao descarte sejam repensados de modo a inspirar significado em seus usuários e a exercer nova função na vida desse indivíduo. Para tanto, buscou-se, a partir de embasamento em estudos existentes sobre as funções básicas dos objetos, experimentar tal prática no contexto de desenvolvimento de um Trabalho de Conclusão de Curso em Design de Interiores, no âmbito do Instituto Federal de Minas Gerais - campus Santa Luzia. Em conclusão, entendemos que a ressignificação é um processo complexo que exige muito estudo, muita criatividade e muita capacidade de percepção e de decodificação do designer.

Palavras Chave: Design de Interiores, função dos objetos, ressignificação.

\begin{abstract}
This paper presents a discussion about the process of furniture and decorative objects' reuse through resignification, aiming for stimulate practices in Interior Design that are aligned with the contemporary sustainability demands. On the opposite way of the planned obsolescence, the excessive garbage production and the indiscriminate use of natural resources, it's necessary to think about the reuse of objects that have lost their meaning and function. Therefore, it was sought, based on existing studies on the function of objects, to try such a practice in the context of the development of a final project for an Interior Design course, run by Federal Institute of Education, Science and Technology of Minas Gerais - campus Santa Luzia. To conclude, we understand that resignification is a complex process and require a lot of study, creativity, sensibility and decode abilities from the designer.
\end{abstract}

Keywords: Interior Design, objects' function, resignification. 


\section{Introdução}

Os objetos são elementos fabricados pelo homem para satisfazer os seus desejos e as suas necessidades; e, para que eles venham a ser adquiridos, eles precisam comunicar "algo" com o indivíduo. Esse processo de comunicação só é possível pois esses objetos são dotados de um sistema que articula as suas funções práticas, estéticas e simbólicas (BÜRDEK, 2010; GOMES FILHO, 2006; LÖBACH, 2001; SCHNEIDER, 2010).

Ocorre que, com o passar do tempo, os objetos podem deixar de comunicar algo aos indivíduos, tornando-se passíveis de descarte por perderem o sentido, por deixarem de pertencer ao conjunto de objetos desejáveis e/ou necessários à vivência de determinada pessoa; seja porque perdeu a sua função, seja porque a sua aparência estético-formal não agrada mais, seja porque a sua imagem simbólica não mais possua significado (BELCHIOR, 2014; LÖBACH, 2001).

Ator fundamental na relação entre consumo e produção, o designer possui o potencial de modificar ou conferir novos valores aos produtos por meio de suas interposições projetuais (DE MORAEIS, 2008). O processo de ressignificação, nesse contexto, possibilita que o designer projete novo significado e novo uso ao modificar as funções do objeto, de modo que um "candidato a descarte" volte a ser um objeto de desejo (BELCHIOR, 2014). Com efeito, a sociedade contemporânea possui conceitos abertos, contínuos e inacabados sobre seus preceitos, padrões e conceitos, nos quais há possibilidade de se criar significados e remanejar valores (HALL, 2005). E mesmo que um produto desenvolva várias funções e possua vários propósitos isso não é impeditivo para que outras possibilidades e outros usos sejam conferidos a esse mesmo produto (NIEMEYER, 2013).

Somado ao exposto, é importante destacar que a ideia de ressignificação de objetos caminha em sentido oposto à estratégia da obsolescência programada, à produção excessiva de lixo e ao uso desenfreado dos recursos naturais, estando essa prática alinhada às demandas contemporâneas de sustentabilidade (BELCHIOR, 2014). Há algumas décadas, a busca por soluções sustentáveis se estabeleceu como parâmetro fundamental de projeto. $\mathrm{O}$ contexto ambiental aplicado à prática do design com a proposta de redução do impacto ambiental de materiais e processos potencializa o Ciclo de Vida do Produto e amplia as atuações do designer (MANZINI; VEZZOLI, 2002).

Visando contribuir para o debate dessa temática, esse estudo busca analisar a prática da ressignificação de móveis e de objetos decorativos descartados como uma possibilidade de ação inserida na práxis do designer de interiores. Com esse intuito, apresentamos os resultados da pesquisa e da ação desenvolvidas para o Trabalho de Conclusão de Curso em Design de Interiores, no contexto do Instituto Federal de Educação, Ciência e Tecnologia de Minas Gerais - campus Santa Luzia.

\section{As funções básicas do objeto}

Baudrillard (2008) defende a ideia de que os objetos transmitem uma mensagem como se tivessem vida própria. Nesse sentido, Schneider (2010) explica que, utilizando as cores, as formas e os materiais, o designer usa de sua criatividade para chegar a uma mistificação estética, fazendo com que o objeto pareça ter "vida própria" e se torne objeto desejado pelo homem. 
Diversos autores (BÜRDEK, 2010; GOMES FILHO, 2006; LÖBACH, 2001; MAIOCCH; PILLAN 2013; SCHNEIDER, 2010) definem a praticidade, a estética e a simbologia como as funções básicas dos objetos, funções essas que lhes conferem a propriedade de comunicar. Conforme nos esclarece Gomes Filho (2006), são essas funções que orientam o designer no processo de desenvolvimento de projetos de produtos. Seguindo essa lógica, Lobach (2001) explica que o designer, na concepção de um produto, otimiza essas funções após analisar as necessidades e as aspirações dos seus futuros usuários, podendo haver a predominância de uma função básica em relação às outras, dependendo da intenção do objeto.

A função prática, segundo Gomes Filho (2006), está relacionada ao uso principal e específico do objeto, às suas questões ergonômicas, de conforto, de eficácia e de operacionalidade. Tem relação com conceitos técnicos e tecnológicos, com os materiais, com o sistema construtivo e de fabricação. Esse conceito também é definido por Schneider (2010), que o nomeia função técnicoprática e o relaciona a questões como manuseabilidade, durabilidade, confiabilidade, segurança, qualidade técnica, ergonomia e valor ecológico. Para Maiocch e Pillan (2013) - que tratam das três supracitadas funções como três componentes e as denominam função, forma e significado - a componente função do artefato refere-se ao seu objetivo, constituído por eficiência, efetividade e demais critérios relevantes ao uso.

Lobach (2001) atribui à função prática dos objetos os seus aspectos fisiológicos de uso, ou seja, por meio das suas funções práticas são satisfeitas as necessidades fisiológicas do usuário, tal como uma cadeira permite o sentar e o descansar. Para Bürdek (2010), que cunha o termo função indicativa, a visualização da função técnica do produto esclarece seu manejo ou manipulação; ou seja, as indicações comunicam ao usuário sobre a forma de utilizar o produto.

Como a configuração de indicações está em relação direta com a função do produto, é este setor da configuração que permite a menor inserção de interpretações individuais ou de pontos de vista pessoais. Dessa forma, a configuração de indicações deve prever consultas aos usuários, seu contexto e experiências (BÜRDEK, 2010, p.312).

Sobre a função estética, Gomes Filho (2006) explica que ela está relacionada à harmonia e à informação visual do objeto; em outros termos: à sua aparência, ao processo de percepção sensorial durante o uso, ao prazer contemplativo por parte do usuário. Schneider (2010) explica que a forma, a cor, o material e a superfície do objeto são aspectos da função estética, pois são responsáveis por conferir a indicação visual ao produto. Segundo Lobach (2001), a estética é o meio de comunicação primário do objeto por ser o primeiro contato (informação visual) que o usuário possui com ele.

Maiocch e Pillan (2013) também definem a componente forma do objeto por sua aparência. Para os autores, do ponto de vista estrutural essa forma deve promover o reconhecimento, por parte do indivíduo, de que determinado produto pertença a um arquétipo específico. Por outro lado, a forma - compreendida como "qualquer tipo de aparência para qualquer tipo de canal sensorial, tal como audição, tato, olfato, paladar" (MAIOCCH; PILLAN, 2013, p.27) - sugere interpretações carregadas de significado.

No processo de comunicação entre objeto e indivíduo, a estética é influenciada pela relação designer-produto-usuário. $O$ designer é o criador do objeto, o produto é o objeto criado e o usuário é o indivíduo que utilizará o objeto. O sentido estético, assim, pode ser mudado dependendo da percepção de cada pessoa. A pessoa que concebe o produto tem uma percepção e objetiva algo; quem está possuindo o objeto, entretanto, pode ter outra percepção (GOMES FILHO, 2006). 
Gomes Filho (2006) defende a ideia de que o objeto deve possuir uma aparência estéticoformal que provoque a atração e o desejo de ser possuído, por necessidade ou não. Lobach (2001) explica que as necessidades surgem quando há uma carência, objetivando restabelecer um estado de tranquilidade. As aspirações, por sua vez, são contrárias às necessidades, não surgem em decorrência de deficiências ou faltas; elas surgem por consequência do curso das ideias. Ambas, no entanto, podem ser satisfeitas por um objeto que passe a ser desejado.

Nesse ponto, cabe destacar que existe uma linha tênue entre a ideia de provocar atração e desejo e de incitar o consumo com fim no próprio consumo. Se, por um lado, é importante que a atratividade e o desejo existam para que uma pessoa se aproprie de determinado objeto e não o queira descartar, por outro é a própria atratividade e o desejo que alimentam o ciclo do consumo e do descarte, já que novas necessidades e novos desejos são criados diariamente a fim de incitar o consumo pelo consumo.

A função simbólica, por fim, está relacionada com as sensações e os aspectos psíquicos do indivíduo em relação ao objeto. É, para Maiocch e Pillan (2013), a interpretação comunicada, capaz de proporcionar emoções. Nas palavras de Bürdek (2010, p.322), o termo simbólico "significa um sinal que por meio de uma combinação (convenção) possui significado intercultural". Encontrado em diferentes contextos (religião, arte, literatura, variedades da vida diária, etc.), o símbolo representa algo não perceptível, de modo que o seu significado seja dado de forma associativa. É, assim, uma função bem complexa porque estabelece uma conexão com experiências e sensações anteriores, envolvendo valores pessoais, sentimentais e fatores sociais, culturais, políticos e econômicos (GOMES FILHO, 2006). Para Schneider (2010), assim como a função estética, a função simbólica de um objeto também pode ser totalmente diferente para cada indivíduo.

Gomes Filho (2006) explica que o estilo visual conduz a uma função simbólica; o conceito da imagem simbólica está relacionado ao significado do produto, incorporando a ele valores culturais e sociais das pessoas e seus estilos de vida. O simbolismo seria, então, o ponto de partida para o desenvolvimento de um produto, pois a aceitação desse produto dependerá da sua conexão com os valores do grupo a que ele será destinado; a intenção é que esse grupo capte e interprete a mensagem que o designer e o design do produto querem transmitir.

Ainda segundo referido autor, algumas influências culturais no estilo de produtos podem durar por muito tempo. Mas há, também, as tendências impostas por eventos, imagens de pessoas influentes e pela mídia em geral que o marketing e a propaganda se encarregam de criar, encorajando os consumidores a acompanhar a moda. Entretanto, Bruno Munari (2015) defende que as coisas deveriam ser pensadas para além do que são, no sentido de como poderiam vir a ser, em que poderiam se tornar ou, também, para que pudesse servir de outra forma. Isso porque muita coisa é jogada fora mesmo podendo ser aproveitada para outra utilidade ou para ser transformada em outra coisa.

Maiocch e Pillan (2013) entendem que as relações técnicas, culturais, emocionais e significativas do produto são compreendidas pelo usuário por meio da percepção, de modo que o indivíduo assimile e incorpore a relação das características da função, estética e simbólica/ significativa do produto criado. 


\subsection{Breves considerações sobre semiótica}

A semiótica tem por objetivo o exame dos modos de constituição de todo e qualquer fenômeno de produção de significação e de sentido (SANTAELLA, 2002). Para que isso aconteça é preciso gerar um estimulo físico (processo interpretativo único e individual) no sujeito, que produz um entendimento mental sobre aquilo (que pode se um objeto) com que foi colocado em contato. A semiose é a relação da interpretação humana sobre esse "algo".

A principal utilidade da semiótica é possibilitar a descrição e a análise da dimensão representativa de objetos, processos ou fenômenos em várias áreas do conhecimento (NIEMEYER, 2013). A semiótica é, assim, o estudo do processo de significação (PIERCE, 1999) e, no campo do Design, auxilia o projetar de atribuições significativas para os produtos que sejam perceptíveis aos clientes/usuários.

As dimensões semióticas inserem-se na relação usuário-produto, através de seus significados denotativo, conotativo e simbólico (GOMES FILHO, 2006). Pode-se dizer que o significado denotativo do objeto é aquele que indica, exprimi, manifesta, revela por meio de notas e sinais. É o significado único, sentido literal do objeto, é a extensão do conceito - como exemplo, maçã = fruta. $O$ sentido conotativo é a relação entre duas ou mais coisas, sentido mais abstrato do objeto. São os vários significados que se pode ter - ainda no exemplo, maçã = tentação, pecado. $\mathrm{E}$ o significado simbólico é a figura pela qual se substitui o nome de uma coisa pelo de um sinal que o uso adotou para designá-la. É um signo mental, está relacionado ao pensamento, à mente, se refere ao objeto por associação de ideias produzidas por uma convenção, assim como maçã =

Os diversos aspectos dos produtos como a aparência estética, a estrutura física e tecnológica, as qualidades de suas superfícies e seus valores sensíveis e emocionais fazem parte do processo de comunicação entre objeto e sujeito. Coerentemente recebendo influência dos diversos fatores socioculturais citados anteriormente, contribuem para produzir variados modos de percepção em relação à leitura e ao uso do produto. O que dá base para essas análises e interpretações são as dimensões semióticas dos objetos, a capacidade que cada objeto tem de comunicar alguma coisa ao usuário.

Schneider (2010) explica que o homem é um ser simbólico que se comunica por intermédio de imagens, gráficos, sinais, números, luzes, sons, gestos, expressões, cheiros, tato, entre outros. Somos seres de linguagem. Linguagem essa que é a representação do mundo, é todo o sistema de produção de sentido difundido pelos meios de representação, como a fotografia, o cinema, o rádio, a televisão, a internet, entre outros.

Para ilustrar a percepção semiótica, Belchior (2014, p.72) diz que "cada produto é uma mensagem ou um predicado que entra em contato com o intérprete. São vários os efeitos que a mensagem pode gerar: ação de compra, emoção, compartilhamento, etc. O grande desafio do designer (...) é gerar uma ação no intérprete a partir de um estímulo". O grande desafio do designer é, em outros termos, produzir (projetar) significado, pois somente assim o objeto conseguirá atingir a linguagem do usuário e poderá ser desejado. 


\section{Ressignificação}

Ressignificação é um processo que consiste em tornar o objeto coerente ao seu possuidor, ou seja, incide em alterar a sua acepção original conforme o contexto vigente, alterando seu conceito, sua percepção e/ou sua interpretação. A ação de ressignificar, por sua vez, atrela-se à ideia de alterar uma ou mais das funções básicas do objeto; alterando-se as suas variáveis, é possível alterar a percepção que temos dos objetos (BELCHIOR, 2014).

Nesse sentido, ressignificar móveis e objetos de decoração descartados consiste em dar um novo significado e um novo uso para o que foi desprezado e que, numa primeira visão, não teria mais utilidade. Para entender esse processo de ressignificação, consideramos o que apontou Baudrillard (2008) sobre o estudo do sistema dos objetos. O autor explica que o sistema de significação vai além da estrutura funcional do objeto e que a expressão funcional não qualifica de modo algum aquilo que se adapta a um fim, mas aquilo que se adapta a uma ordem ou a um sistema. Para o referido autor não é só a praticidade do objeto que precisa ser considerada, mas também as suas combinações, cores e estilos, considerando-os parte de um jogo em um sistema universal de significados.

O processo de ressignificação, então, deve considerar o sujeito e o contexto em que ele está inserido; formas de vivência, valores, padrões, identidade. Reyes (2010) define o conceito de identidade como a soma de valores que torna determinado indivíduo e sociedade únicos, mas não obrigatoriamente fixos. Em analogia, a identidade é uma linha mestra que possui valores originais e que se modifica e se transforma com o passar do tempo. Assim também, a partir do processo de ressignificação, os objetos podem ter sua identidade e sua simbologia alteradas, apresentando novas identificações.

Belchior (2014) acredita que a partir de muito estudo e criatividade o designer pode adquirir a capacidade de transformar o inútil em objetos funcionais, de grande apelo estético e com forte simbologia. Ele ainda ressalta que, a partir do momento em que essa cultura da ressignificação se expandir, o descarte desnecessário diminuirá. Assim, da mesma forma com que o design contribuiu para a instauração do consumismo, ele pode ser ferramenta para trazer ao objeto descartado o simbolismo para que ele volte a ser um objeto de desejo.

\section{Procedimentos metodológicos}

O objetivo desta pesquisa é analisar o processo de ressignificação de um objeto por meio de um projeto de Design. A investigação desenvolveu-se no âmbito do IFMG - campus Santa Luzia, na forma de trabalho de conclusão de curso para o curso superior de tecnologia em Design de Interiores.

Quanto aos procedimentos técnicos, optou-se pela pesquisa bibliográfica seguida de estudo de campo. Na pesquisa bibliográfica buscou-se compreender a ideia de ressignificação sob a ótica do Design, bem como as ações necessárias para sua promoção a partir da compreensão das funções dos objetos. O estudo de campo consistiu em desenvolver e analisar o processo de projetação de ressignificação de um objeto para determinado público de interesse, que compreendeu as seguintes etapas: 1) identificação do público de interesse e análise do perfil sociocultural deste grupo; 2) seleção de um objeto de decoração ou móvel com potencial de ressignificação, coerente com o público em comento; 3) compreensão da significação do objeto por parte desse público; 4) 
projetação de ressignificação do objeto seguindo processo de Design; 5) execução do projeto de ressignificação; 6) compreensão da significância do objeto ressignificado por parte dos indivíduos participantes das etapas um e três; e 7) análise dos resultados.

$\mathrm{Na}$ primeira etapa definiu-se o grupo de interesse e aplicou-se uma entrevista semiestruturada para identificação do perfil sociocultural deste grupo, constituído de nove integrantes. As entrevistas foram individuais e objetivaram conhecer informações pessoais dos indivíduos, como grau de escolaridade, hobbies, características socioeconômicas, situação familiar, atividades profissionais, preferências culturais e, em especial, suas melhores lembranças do passado, suas memórias afetivas.

Na segunda etapa selecionou-se, dentre as opções de objetos de decorações ou móveis abandonados, subutilizados ou degradados identificados, um móvel abandonado que havia perdido, para o seu dono, a sua utilidade.

Na terceira etapa objetivou-se analisar a percepção do grupo de interesse em relação à praticidade, à estética e à simbologia do objeto. Para tanto, utilizou-se a técnica de pesquisa de grupo focal, que compreende sessões grupais de discussão, centralizando um tópico específico a ser debatido entre os participantes. Essa técnica foi escolhida por ser indicada para pesquisas que analisem atitudes, preferências e sentimentos (MICHEL, 2009). Realizou-se uma única sessão, conduzida por uma moderadora (a pesquisadora) e uma auxiliar (a orientadora). A discussão foi direcionada pelas seguintes perguntas em relação ao objeto exposto no ambiente: $O$ que é esse objeto? O que ele significa? Ele te faz lembrar algo? Você compraria este objeto? Por quê? Quanto você pagaria por este objeto? Você daria este objeto a alguém? Por quê? Você colocaria este objeto em algum lugar da sua casa? Por quê? Para registro das informações obtidas, foram feitas anotações e gravação das falas dos integrantes do grupo. Na sequência, essas informações foram analisadas e comparadas com o estudo teórico desenvolvido.

$\mathrm{Na}$ quarta etapa foi desenvolvido um projeto de Design buscando ressignificar o objeto em estudo. Em primeiro lugar, formulou-se um conceito de Design a partir do perfil sociocultural identificado e do que o objeto comunicou aos integrantes do grupo focal. O conceito gerado direcionou o projeto para que o objeto pudesse ter de volta o valor de objeto de desejo e passasse a fazer sentido para aquele público.

$\mathrm{Na}$ quinta etapa, o projeto foi executado seguindo o conceito desenvolvido. A execução abarcou as seguintes etapas: 1) a peça passou por um redesenho a partir do seu desenho primário; 2) fotografou-se a peça em vistas e, após impressão destas vistas, desenhou-se sobre elas e criouse seu novo design; 3) foram escolhidos os materiais utilizados para executar o projeto, a partir da ideia do reuso; e 4) foram realizadas todas as intervenções necessárias à execução, tais como limpeza, polimento, pintura, aplicação de revestimento, entre outros.

Na sexta etapa do estudo de campo, realizou-se mais uma sessão de grupo focal, formada pelos integrantes da primeira sessão, visando exibir o objeto já ressignificado e incitar uma discussão comparativa, guiada pelas seguintes questões: $O$ que é esse objeto? $O$ que ele significa? Ele te faz lembrar algo? Você compraria este objeto? Por quê? Quanto você pagaria por este objeto? Você daria este objeto a alguém? Por quê? Você colocaria este objeto em sua casa? Por quê? O que mudou neste objeto? Você acha que ele ficou melhor esteticamente? Assim como na etapa três, foram anotadas todas as observações e gravadas as falas dos integrantes dos grupos. 
Na sétima e última etapa realizou-se a análise dos resultados para verificar se o processo de ressignificação foi desenvolvido com satisfação, ou seja, se o objeto ressignificado tornou-se um objeto de desejo para aqueles indivíduos.

\section{Análise de resultados}

\subsection{Perfil dos participantes}

O grupo de interesse foi constituído por estudantes do curso de Design de Interiores do Instituto de Federal de Educação, Ciência e Tecnologia de Minas Gerais - IFMG. Os entrevistados, de modo geral, possuem como características em comum algumas lembranças do passado relacionadas a uma infância longe de violência, com brincadeiras de rua, contato com a natureza e vivência na casa dos avós, com familiares. Nesse contexto, nos chamou a atenção a forte presença do termo casa de avó, vinculada a um quintal e ao contato com a natureza, natureza essa também presente nas lembranças de viagens vividas e de viagens planejadas para o futuro.

\subsection{Seleção do objeto com potencial de ressignificação}

Elegeu-se uma mesa de telefone dos anos 1980 (Figura 1), que na época servia de apoio para telefone fixo e catálogos telefônicos, e que atualmente se encontrava subutilizada e degradada. Este objeto é antigo e testemunha a história da expansão do uso do telefone no Brasil, além da história pessoal que motivou a sua compra na década de 1980.

Figura 1 - Mesa de telefone dos anos 1980, eleita para ressignificação.

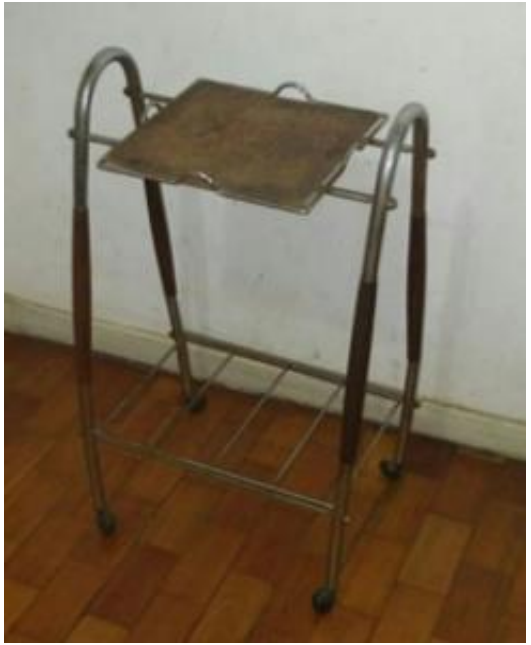

Fonte: acervo pessoal.

Essa mesa foi comprada após o senhor $\mathrm{X}$ ter adquirido uma linha de telefone fixo. $\mathrm{O}$ serviço de telefonia, na época, era muito caro e demorado de se obter. Embora já tivesse pago pelo serviço, o senhor X precisou aguardar um bom tempo pela disponibilização da linha. Quando recebeu a notícia de que a mesma já havia sido liberada, o senhor $X$, recém-casado, resolveu então fazer uma surpresa para a esposa. Apesar do alto preço pago pela linha de telefone, ele não hesitou em comprar também uma mesa apropriada para o uso, onde colocaria o telefone, levando consigo para a casa os bens adquiridos. 


\subsection{O primeiro grupo focal}

Neste grupo focal, conforme previsto, investigou-se a percepção do público de interesse em relação às funções básicas do objeto 'mesa de telefone'. Essa sessão realizou-se no dia 27 de junho de 2017, às 19h30, nas dependências do IFMG - campus Santa Luzia. Após o móvel ter sido colocado sobre a mesa para ficar exposto ao grupo, foram feitas as perguntas relatadas nos procedimentos metodológicos, adaptadas conforme a conversa ia se desenrolando.

Importante relatar que, de início, a maioria dos integrantes não compraria a mesa e nem a queria de graça; porém, não a jogariam fora, apesar de concordarem entre si que hoje, como mesa de telefone, ela não teria mais utilidade, já que a maioria dos participantes não possui telefone fixo e os catálogos impressos se tornaram praticamente relíquias. Entretanto, o valor monetário que dariam pelo objeto aumentou consideravelmente após conhecerem a sua história, apesar de já terem percebido que se tratava de um objeto antigo pelo seu aspecto estético (material e forma). Essa estética remeteu a alguns integrantes a lembrança da casa dos avós.

Ao analisar a discussão percebeu-se que a carga histórica do objeto possui grande importância para o grupo, reforçando o que nos diz Baudrillard (2008) sobre os objetos antigos. 0 autor compreende esses objetos como testemunhas de vivência de um tempo passado, sendo totalmente dotados de significado por possuírem um propósito de lembrança e nostalgia.

A discussão também corroborou com o que Gomes Filho (2006), Baudrillard (2008) e Belchior (2014) discutem quando apontam que os "significados são aprendidos pela sociedade e se expressam por meio das atitudes, dos vários comportamentos da coletividade e dos valores de cada indivíduo e assim originam novos significados" (BELCHIOR, 2014, p.93). Com efeito, os integrantes do grupo focal observaram que o móvel exposto pertencia a um outro contexto por possuir materiais e formas distintas das de hoje, como o tipo de madeira, o metal e as curvas.

Schneider (2010, p. 11) explica que "toda vez que produtos são comprados e usados, eles assumem caráter simbólico ou sígnico, começam a transmitir significados e valores". Isso pode ser identificado na mudança da percepção de valor do móvel pelos participantes, quando souberam um pouco de sua história pessoal e social.

\subsection{A proposta de ressignificação do objeto}

Levou-se em consideração o que o objeto comunicou aos integrantes do grupo focal, o perfil sociocultural identificado, os elementos práticos, estéticos e simbólicos percebidos pelos integrantes e a historicidade do móvel escolhido. Tudo isso direcionou o projeto para que o objeto pudesse ter de volta o valor de objeto de desejo e passasse a fazer sentido para o grupo.

Após análises, entendeu-se que a ideia de um suporte de plantas para espaços reduzidos seria uma boa proposta de uso, visto que proporcionaria aos indivíduos do grupo de interesse certo contato com a natureza, o que, para eles, é extremamente importante. Proporcionaria, também, a possibilidade de trazer um pouco do quintal de suas infâncias para dentro de casa, já que as suas atuais residências são verticalizadas e reduzidas. 
Assim, desenvolveu-se um painel de estudo de semelhantes (Figura 2) para direcionar o conceito do projeto, buscando compreender a linguagem estética associada ao grupo de interesse. Foram feitos diversos croquis de possíveis soluções. Decidiu-se por manter os elementos estéticos da mesa, porém revitalizados. Conforme previsto, a escolha dos novos materiais a serem utilizados baseou-se na ideia da reutilização. Nesse sentido, a madeira agregada ao projeto foi também recolhida de descartes, assim como os vasos menores que foram reutilizados.

Figura 2 - Painel de estudo de semelhantes.

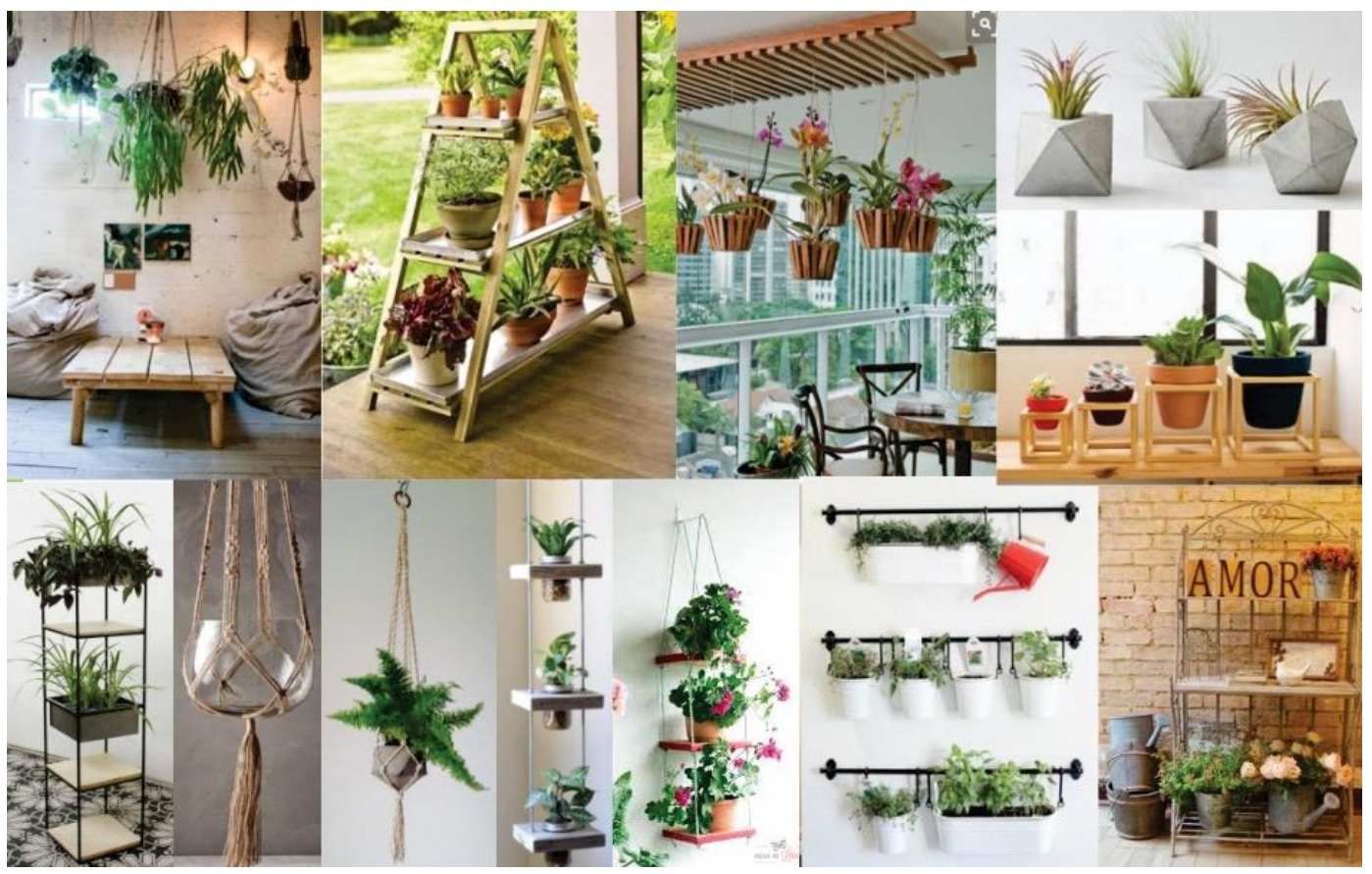

Fonte: acervo pessoal.

Na execução do projeto primeiramente foi realizada a limpeza do móvel com água morna, detergente, lã de aço e pano para a retirada de resíduos depositados ao longo do tempo, tanto na estrutura de ferro como na parte de madeira. Após a limpeza, a mesa foi lixada com uma lixa no 180 e, posteriormente, com uma lixa no 240 para a retirada de ferrugem e outras impurezas que não foram possíveis de serem retiradas com a limpeza. A seguir, pintou-se a estrutura de ferro com tinta metalizada cromada visando manter a cor e o brilho originais da peça. A madeira dos pés foi envernizada com verniz fosco para deixar o brilho somente na estrutura cromada. A madeira do tampo superior recebeu uma laminação e verniz para reavivar a madeira existente. Os suportes que sustentam o tampo também viraram suportes para ganchos de pendurar vasos, e as grades inferiores viraram suporte para fixar cachepôs que acomodam vasos de plantas variadas. 0 resultado pode ser visualizado na Figura 3. 
Figura 3 - Móvel ressignificado.

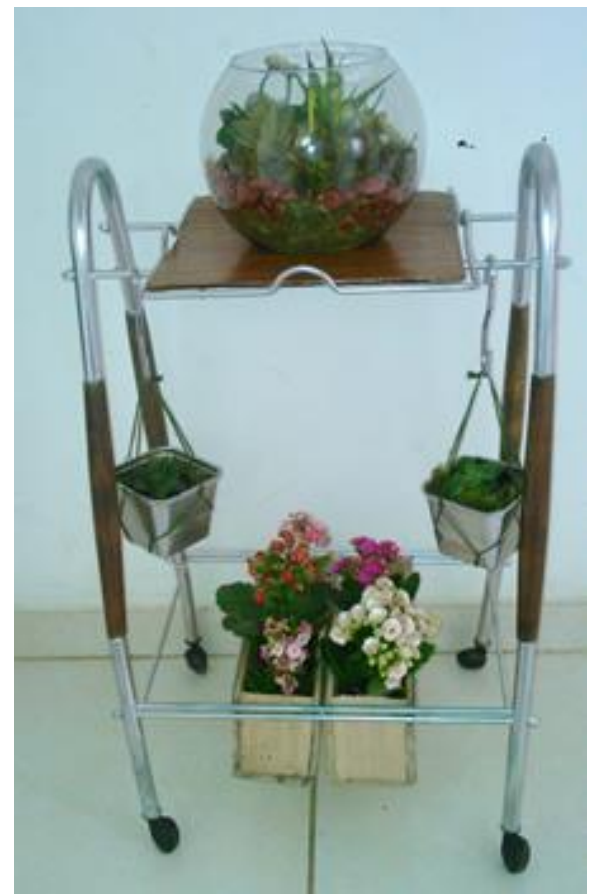

Fonte: acervo pessoal.

\subsection{O segundo grupo focal}

A segunda sessão de grupo focal realizou-se no dia 18 de julho de 2017, às 19h00, também nas dependências do IFMG - campus Santa Luzia, contando com apenas sete dos nove integrantes iniciais, a pesquisadora e a orientadora.

O móvel foi colocado sobre a mesa para ficar exposto ao grupo. Nesse momento algumas pessoas manifestaram vontade de levar o móvel para casa dizendo ter ficado bonito. Após observação das reações, foram feitas as perguntas relatadas nos procedimentos metodológicos, adaptadas conforme a conversa ia se desenrolando, e incitou-se uma discussão comparativa.

Um dos integrantes do grupo focal disse que o móvel parecia estar no momento como um suporte de plantas e não parecia ser um suporte de plantas, ou seja, ele poderia ser uma outra coisa, não apresentando somente uma função. Ainda observou que ele poderia ter outros elementos que caracterizassem com mais clareza o seu uso como suporte de plantas. Duas outras pessoas enxergaram o móvel como um suporte de plantas e as outras enxergaram como mesa de apoio. Há, pois, um ruído nessa comunicação, pois o grupo não entendeu de forma clara o novo uso dado ao móvel. Entretanto, todos concordaram que a ideia do suporte de plantas tinha sido muito boa e que fazia sentido para eles.

Analisando a discussão, ficou claro que, para os integrantes do grupo focal, a revitalização do móvel agregou valor financeiro a ele. Porém, é preciso assinalar que o móvel ganhou maior valor monetário não porque ele vira um suporte de plantas (ressignificação), mas porque ele está revitalizado. 
Observou-se, também, que não foi alcançado o objetivo de o móvel tornar-se um objeto de desejo, afinal, quase metade dos integrantes não o comprariam e nem o colocariam em suas casas por ele não combinar com o estilo (gosto) deles. Talvez, para se ter explorado de forma satisfatória a linguagem estética esperada, dever-se-ia ter usado materiais mais nobres, como a madeira de demolição e vasos de cimento reutilizados. Com isso, percebe-se a importância de se entender o outro e de saber trabalhar a linguagem das referências (painel de semelhantes) para que o trabalho siga a mesma linguagem.

\section{Considerações finais}

Este estudo apresentou uma discussão sobre o processo de ressignificação de móveis e objetos de decoração. Na pesquisa de campo, que buscava exercitar referido processo, concluiu-se que o objeto ressignificado não comunicou com eficácia as funções básicas pretendidas para o móvel.

A função prática não foi compreendida por muitos; algumas pessoas não enxergaram com clareza a transformação da mesa de telefone em um suporte de plantas. Entenderam que aquele seria um objeto reaproveitado com múltiplas utilidades, bastando trocar o que se expõe - plantas, livros, luminária ou uma bandeja de lanche. A linguagem estética empreendida não dialogou com a linguagem de estilo e de personalidade dos integrantes, pois quase metade deles não manifestou desejo de adquirir o móvel e levá-lo para casa. Em relação à significação do objeto, apesar da ideia do suporte de plantas ter feito muito sentido para o grupo, não foi o suficiente para apresentarem o desejo de possuí-lo.

O grande ganho nesse processo foi a revitalização do móvel. Entretanto, entendemos, a partir das referências consultadas, que revitalizar não é ressignificar. Os participantes do grupo focal passaram a dar mais valor monetário ao objeto por causa de sua revitalização, e não devido à sua nova função prática e à sua nova função estética.

Isso nos mostra que o processo de ressignificação é complexo e que, como explicado por Belchior (2014), exige muito estudo e criatividade do designer. É preciso ter bastante esmero, e até certa experiência, em todas as etapas do processo para que não haja interferência na comunicação entre o objeto e o seu possível usuário. Entende-se, também, ser necessário desenvolver e aprimorar técnicas de Design que visem facilitar a difícil tarefa de compreender o comportamento humano. Como designers projetam para o outro, tal capacidade de percepção e de decodificação é imprescindível.

\section{Referências}

BAUDRILLARD, Jean. O sistema dos objetos. 5.ed. São Paulo: Perspectiva, 2008.

BELCHIOR, Camilo. Reciclando os sentidos. Contagem: Ed. do Autor, 2014.

BÜRDEK, Bernhard E. Design: história, teoria e prática do design de produtos. São Paulo: Blucher, 2010.

DE MORAES, Dijon. Design e complexidade. In: Cadernos de Estudos Avançados em Design: Design e Transversalidade. Belo Horizonte: Santa Clara: Centro de Estudos Teoria, Cultura e Pesquisa em 
Design. UEMG, 2008.

GOMES FILHO, João. Design do objeto: bases conceituais. São Paulo: Escrituras Editora, 2006.

HALL S. A identidade cultural na pós modernidade. 10.ed. Rio de Janeiro: DP\&A, 2005.

LöBACH, Bernd. Design Industrial - Bases para a Configuração dos Produtos Industriais. São Paulo: Blucher, 2001.

MAIOCCH, Marco; PILLAN, Margherita. Design emocional (ou simplesmente design?). In: Cadernos de Estudos Avançados em Design: Design e Emoção. Barbacena: EdUEMG, 2013.

MANZINI, Ezio; VEZZOLI, Carlo. O Desenvolvimento de produtos sustentáveis: os requisitos ambientais dos produtos industriais. São Paulo: Edusp, 2002.

MICHEL, Maria Helena. Metodologia e pesquisa científica em ciências sociais. 2ed. São Paulo: Atlas, 2009.

MUNARI, Bruno. Das coisas nascem coisas. 3.ed. São Paulo: Martins Fontes, 2015.

NIEMEYER, Lucy Niemeyer. Elementos da semiótica aplicada ao design. Rio de Janeiro: 2AB, 2013.

PEIRCE, Charles S. Semiótica. 3.ed. São Paulo: Editora Perspectiva, 1999.

REYES, Paulo. Identidade $\mathbf{x}$ identidades: uma visão pelo design. In: Cadernos de Estudos Avançados em Design: Design e Identidade. Barbacena: EdUEMG, 2010.

SANTAELLA, Lucia. Semiótica Aplicada. São Paulo: Thomson, 2002.

SCHNEIDER, Beat. Design - Uma introdução: o design no contexto social, cultural e econômico. São Paulo: Blücher, 2010. 